\title{
Identifying high-value areas to strengthen marine conservation in the channels and fjords of the southern Chile ecoregion
}

\author{
Alejandro R. Vila, Valeria Falabella, Mauricio Gálvez, Aldo Farías \\ Daniela Droguett and Bárbara SaAvedra
}

\begin{abstract}
Although Chile has been establishing marine protected areas since the 1960 s, studies to identify representative areas for marine biodiversity conservation at the ecoregional scale are lacking. Using the Marxan decision support tool we conducted a systematic planning process to identify High Conservation Value Areas in the channels and fjords of the southern Chile ecoregion. We involved 74 experts and other stakeholders in identifying conservation features, setting targets and compiling distribution data. Current distributions of 39 features were used in Marxan analyses. In one scenario we locked planning units that contained the Francisco Coloane Marine Protected Area. In a second scenario we also excluded planning units that overlapped with Appropriate Areas for Aquaculture, defined by the Chilean government's coastal zoning process. One-hundred percent of the proposed conservation targets were met in both scenarios. Although the distribution of 12 conservation features overlapped to a certain extent $(>10 \%)$ with Appropriate Areas for Aquaculture, Marxan identified conservation solutions avoiding these areas. Our suggested portfolio of High Conservation Value Areas comprises a network of 33 sites, covering $99,432 \mathrm{~km}^{2}$ ( $12 \%$ of the ecoregion). These results provide the first science-based roadmap for decision makers and conservationists, and were used by the Chilean government in its coastal zoning process to define priority areas for conservation. Consequently, salmon farming has been excluded from Tierra del Fuego island.
\end{abstract}

Keywords Channels and Fjords ecoregion, High Conservation Value Areas, Marxan, Patagonian Sea, salmon farming, systematic conservation planning

\footnotetext{
Alejandro R. Vila (Corresponding author), Daniela Droguett and Bárbara SAAvedra Wildlife Conservation Society-Chile, Balmaceda 586, Punta Arenas, Chile. E-mail avila@wcs.org

Valeria Falabella Wildlife Conservation Society-Sea \& Sky Project, Marine Program, Buenos Aires, Argentina

Mauricio Gálvez ${ }^{*}$ and Aldo Farías $\dagger$ World Wildlife Fund-Chile, Santiago, Chile

${ }^{*}$ Current address: Subsecretaria de Pesca y Acuicultura, Gobierno de Chile, Valparaíso, Chile

†Current address: Subsecretaria de Turismo, Unidad de Territorio y Sustentabilidad, Santiago, Chile

Received 24 March 2014. Revision requested 27 June 2014.

Accepted 7 October 2014. First published online 12 February 2015.
}

This paper contains supplementary material that can be found online at http://journals.cambridge.org

\section{Introduction}

Tnternational conservation efforts aim to protect the Loceans within representative systems of marine protected areas, encompassing at least $10 \%$ of coastal and marine areas by 2020 (CBD, 2011). However, the rate of progress has been insufficient to reach this target, and therefore additional efforts are needed (Spalding et al., 2008; Toropova et al., 2010). Many biogeographical provinces are under-protected within the existing network of marine protected areas in Latin America and the Caribbean region (Guarderas et al., 2008), and of particular concern are the unprotected marine areas of the South Pacific and South Atlantic coasts of Latin America (Guarderas et al., 2008; Spalding et al., 2008; Wood et al., 2008; Toropova et al., 2010).

The Chilean coast of Patagonia is one of the most extensive fjord regions (Pantoja et al., 2011), and unique oceanographic conditions and coastal heterogeneity have resulted in high levels of endemism in invertebrates (Häussermann \& Försterra, 2009; Miloslavich et al., 2011). The region is also home to rare and endemic species, such as the Chilean dolphin Cephalorhynchus eutropia, the southern sea otter Lontra felina and the southern river otter Lontra provocax, and contains critical habitats for marine mammals of global conservation concern (Aguayo-Lobo et al., 2007). There are 18 marine Important Bird Areas in the region (BirdLife International, 2004; Falabella et al., 2009; Soazo et al., 2009).

Although these fjord ecosystems provide important services to humans, they have not been adequately valued (Iriarte et al., 2010). Small-scale and industrial fisheries, as well as tourism, are growing in southern Chile. The increase in poorly managed aquaculture, especially of exotic species, warrants particular attention (Fernández \& Castilla, 2005). There has been significant growth in salmon farming (León Muñoz, 2006), and by 2006 Chile was the second largest exporter of salmon. However, the industry has been characterized by poor labour conditions and environmental degradation (Buschmann et al., 2006; Díaz Herrero \& León Muñoz, 2006). As a consequence of its rapid growth, and an outbreak of salmon anaemia virus in 2007, the industry plans to expand further into Chilean Patagonia to avoid 
reinfections. Faced with the prospect of having to grant thousands of concessions for salmon farming the government decided to produce a coastal zoning plan and declared a 2-year moratorium on aquaculture. This zoning, and the definition of preferential areas for aquaculture, was carried out during 2009-2011, and aquaculture concessions can now be granted.

Chile's approach to establishing marine protected areas has been uncoordinated and the current arrangement and sizing of existing marine protected areas is flawed (Fernández \& Castilla, 2005). According to a gap analysis only $0.3 \%$ of its marine and coastal areas and $0.03 \%$ of its exclusive economic zone were protected (IEB, 2010). However, the designation of Motu Motiro Hiva Marine Park in 2010 increased this protection to $4.3 \%$ (Friedlander et al., 2013). Coarse-scale assessments of existing marine protected areas, and analyses to identify priority areas for the conservation of marine biodiversity, have concluded that to meet representation targets for biodiversity features an extended network is needed, resulting from a systematic conservation planning approach (Tognelli et al., 2005, 2009; IEB, 2010; Leiva et al., 2010).

Here we present the results of a participatory sciencedriven process to identify areas of high value for marine conservation in the channels and fjords of the southern Chile ecoregion (Spalding et al., 2007). We incorporated the most comprehensive information available on the distribution of biodiversity features, which will inform future marine conservation efforts in this ecoregion. We also evaluated the overlap between key species and habitats with proposed aquaculture areas to identify potential conflicts between conservation and the development of this industry.

\section{Study area}

Our study area comprises the channels and fjords of the southern Chile ecoregion (Fig. 1), which includes the inshore and offshore waters of southern Chile, and a small portion of the southernmost Atlantic coastal and shelf waters of Argentina. It covers $897,000 \mathrm{~km}^{2}$, extending up to 200 nautical miles from the shore in most areas.

\section{Methods}

In 2009 we initiated a systematic planning process (Margules \& Pressey, 200o) to identify High Conservation Value Areas for marine and coastal biodiversity of the channels and fjords of the southern Chile ecoregion. Our approach was based on the best available information and the involvement of various experts, who participated in two workshops. The first workshop was held in May 2009 in Santiago, Chile, to facilitate local scientists and managers to identify conservation features (species, habitats and processes) and to define conservation targets (the proportion to be conserved). It was attended by 35 participants (Supplementary Table $\mathrm{S}_{1}$ ). The second was held in September 2009 in Punta Arenas, Chile, bringing together 39 participants (Supplementary Table $\mathrm{S} 1$ ) to analyse the proposed conservation features and targets and to discuss the available distribution data. Interviews of workshop participants were also conducted to supplement data collection.

\section{Conservation features and quantitative targets}

Georeferenced datasets of the conservation features were analysed using ArcGIS v. 10 (ESRI, Redlands, USA) and the extensions $3 D$ Analyst, Geostatistical Analyst and Spatial Analyst. Forty-six layers of spatial information on the distribution of 39 features were used to conduct Marxan analyses (Supplementary Tables $\mathrm{S}_{2} \& \mathrm{~S}_{3}$ ).

A conservation target is the amount of the spatial attribute of each feature that planners attempt to capture in the network of conservation areas. The rationale for setting specific targets is not well developed and the commonly used targets are arbitrary (Pressey et al., 2003). Targets were established following the method proposed by Galvez et al. (2010), which is based on expert evaluation of the current status of each feature, its vulnerability and the extent of its occurrence in the ecoregion.

Targets were expressed as percentages (Supplementary Table S2). Any feature targeted $100 \%$ will act as a seed in Marxan and will therefore bias the analysis towards these areas (PacMARA, 2010). For this reason planning units of features with targets of $100 \%$ were added manually to the final solution (PacMARA, 2010).

\section{Selection of High Conservation Value Areas}

High Conservation Value Areas were identified using Marxan v. 2.43 (Ball \& Possingham, 2000; Possingham et al., 2000; Ball et al., 2009) and Zonae Cogito (Segan et al., 2011). We used Marxan to select a network of planning units such that the total cost of the network was minimized (Ball \& Possingham, 2000). We parametrized Marxan to identify networks of High Conservation Value Areas that met all targets while attempting to minimize the size of the network and keep it reasonably compact/connected (Ball \& Possingham, 2000; Possingham et al., 2000).

We divided our planning region into two areas: (1) continental shelf (up to the $1,000 \mathrm{~m}$ isobath), and (2) open ocean (beyond the 1,00o $\mathrm{m}$ isobath). Hexagonal planning units of 50 and $200 \mathrm{~km}^{2}$ were used for the continental shelf and the open ocean, respectively. The smaller planning units were used to capture the detail and complexity of channels and fjords on the continental shelf. A total of 9,746 planning units were identified: 3,666 in the oceanic 


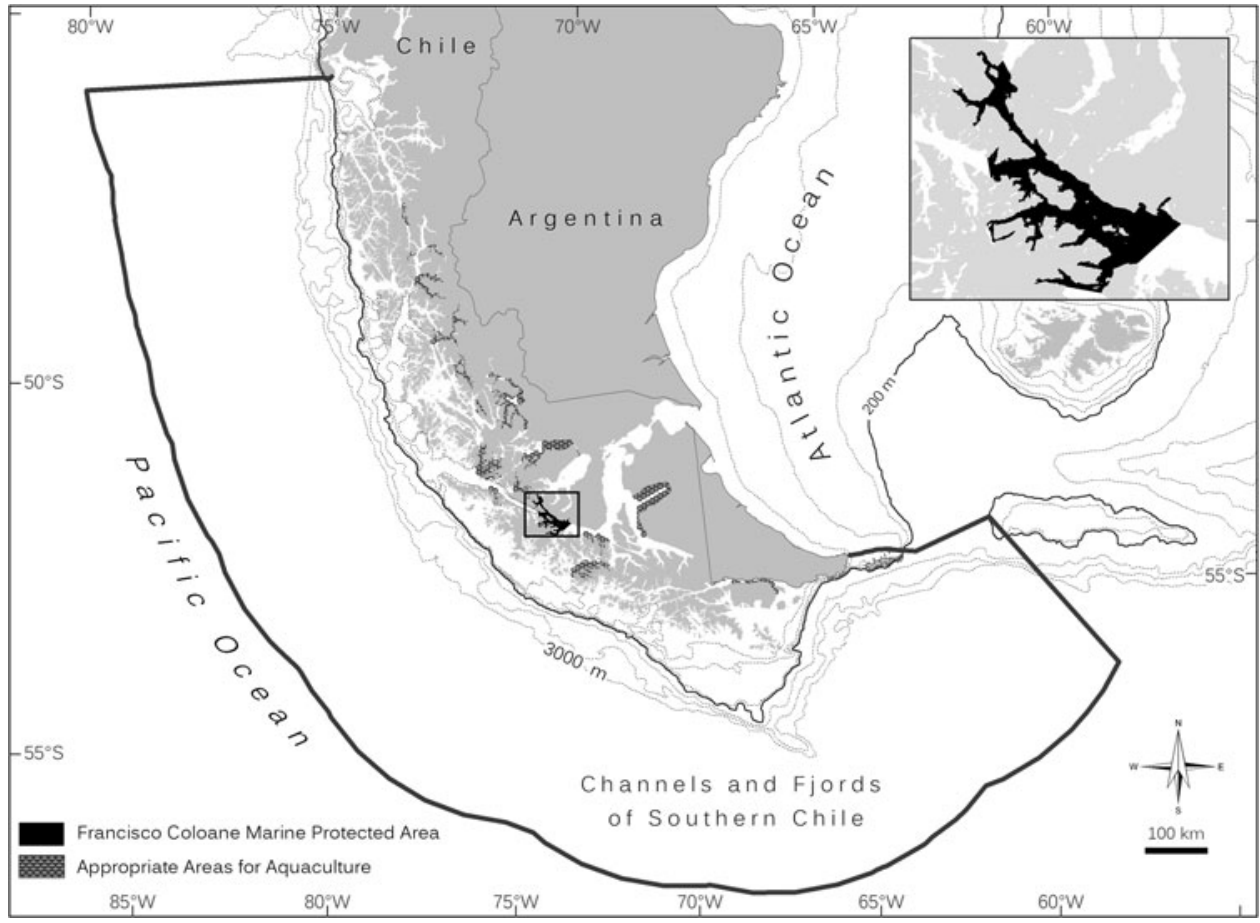

FIG. 1 The channels and fjords of the southern Chile ecoregion, showing the locations of the Francisco Coloane Marine Protected Area (inset) and Appropriate Areas for Aquaculture. area, 5,879 on the continental shelf, and the others on the border between these areas.

We conducted the analysis following the guidelines proposed by Ardron et al. (2010). We used the Zonae Cogito calibration tool to find an efficient range of boundary length modifier and species penalty factor values to ensure all targets were met. The species penalty factor parameter must be set so that penalties for missing conservation targets are scaled appropriately (Ardron et al., 2010). The boundary length modifier controls the clustering of selected areas in individual solutions (McDonnell et al., 2002; Ardron et al., 2010). We set the boundary length modifier at 0.2 and the species penalty factor at 10. For each of our two scenarios (see below) we produced 400 Marxan runs, involving 10 million iterations.

As every planning unit has a cost, the Marxan solutions attempt to meet all conservation targets with a minimum total cost (opportunity, management and acquisition costs). Cost setting can be used to promote the selection of planning units in certain areas (i.e. in areas where it is presumably less difficult to exclude human activities). We therefore took into account the growing pressure of human activities on coastal and inland waters, and the potential conflicts of interest among various stakeholder groups. We then assigned high cost value to planning units located in these waters. We assigned the oceanic planning units a base cost of 200 units. The planning units located in coastal and inland waters were assigned a cost of 400 units, assuming higher usage and a higher degree of conflict than in the open ocean, and thus promoting the selection of offshore planning units.
We produced Marxan solutions for two planning scenarios. In scenario I we locked in all planning units that overlapped with Francisco Coloane Marine Protected Area (Fig. 1), which is the only marine protected area in the ecoregion and was designated in 2003 to protect the feeding ground of the humpback whale Megaptera novaeangliae in Chilean Patagonia. The remaining planning units were available for selection and were included in the solution. In scenario II we took into account the Appropriate Areas for Aquaculture, defined by the government (Serplac et al., 2005; Gobierno Regional, 2011a,b,c). We sought a solution that would avoid these conflict areas, already designated for salmon farming, and therefore we excluded from the analysis all planning units that were designated as Appropriate Areas for Aquaculture (Fig. 1). We also evaluated the distribution of the conservation features in those areas, to identify the species or habitats that would potentially be affected by aquaculture. We also locked in the units that overlapped with the Francisco Coloane Marine Protected Area (Fig. 1).

For each scenario we obtained a portfolio of High Conservation Value Areas by using the best Marxan solution (the solution with the lowest cost). To compare the solutions of both scenarios we used Pressey's measure of efficiency (Pressey \& Nicholls, 1989; Stewart et al., 2003) and the index of compactness proposed by Possingham et al. (2000). Efficiency (E) determines the aptitude of the model to meet the conservation targets, whereas compactness assesses the degree of spatial clustering in the portfolio. $E=1-X / T$, where $X$ is the number of planning units needed to meet the constraints and $T$ is the total number of 
planning units. It ranges from o to 1 (the most efficient solution). The compactness was estimated as ratio $=$ boundary length $/ 2 \sqrt{ } \pi \times$ area.

We proposed High Conservation Value Areas based on the sites selected in the best solution for scenario II. These sites included patches of two or more connected or immediately adjacent planning units. Isolated and remote planning units with few opportunities for implementing effective management or conservation actions were excluded from this proposal.

\section{Results}

The Marxan solutions include planning units in both oceanic and coastal areas (Fig. 2). All of the proposed conservation targets were met in both scenarios. For scenario I the total number of planning units selected was 1,148 1,516. In scenario II the solutions included $1,213-1,655$ planning units. Areas of high selection frequency (i.e. planning units selected in a high proportion of the 400 simulations) were similar in both scenarios (Fig. 2). Groups of 220 and 243 planning units were selected in all the solutions obtained for scenarios I and II, respectively, and were therefore necessary to meet our targets. Ninety-one percent of the planning units selected in all simulations in scenario I were also the highest selected planning units in scenario II, and there was also a high degree of correspondence $(86 \%)$ of planning units with high selection frequency $(80-90 \%)$ in both scenarios.

The best solution for scenario I included 1,485 planning units, covering $123,225 \mathrm{~km}^{2}$, with a perimeter of $4,844 \mathrm{~km}$. The best solution for scenario II included 1,452 planning units, covering $112,778 \mathrm{~km}^{2}$ (8.5\% smaller than scenario I, although the perimeter was $10 \%$ larger). The compactness in scenario I was higher than in scenario II (3.9 vs 4.5). Both scenarios showed the same efficiency to meet the targets (0.85). Thus the exclusion of the units assigned to Appropriate Areas for Aquaculture did not translate into a greater difficulty to meet the targets in terms of efficiency.

\section{Overlap of Appropriate Areas for Aquaculture and conservation features}

In scenario II we considered 115 Appropriate Areas for Aquaculture $\left(3,288 \mathrm{~km}^{2}\right)$. The exclusion of 380 planning units located in these areas was not a constraint to meeting all of our 46 conservation targets. However, the identified sites differed in size and shape, and the outputs added five small clusters of planning units $100 \%$ selected in the simulations that were necessary to fulfil the targets (Fig. 2).

When we compared the distribution of the Appropriate Areas for Aquaculture with the extent of occurrence of each feature we found that several species or habitats overlapped with these areas; the distribution of 12 features overlapped the areas by $\geq 10 \%$ (Fig. 3), including the endemic Chilean dolphin and the feeding areas of the humpback whale. The fjords without glacial influence had the highest overlap with the Appropriate Areas for Aquaculture $(65 \%$ of their range intersect these areas), although it was still possible to meet the conservation target for this feature using planning units outside the Appropriate Areas for Aquaculture.

\section{Proposed portfolio of High Conservation Value Areas}

The suggested portfolio of High Conservation Value Areas is a network of 33 sites comprising patches of two or more connected planning units (Fig. 4), based on the best solution obtained for scenario II. This network includes 31 sites on the continental shelf and two in the oceanic area, covering $99,432 \mathrm{~km}^{2}$, or $12 \%$ of the ecoregion (Supplementary Table S4). The portfolio covers $45,204 \mathrm{~km}^{2}(27.7 \%)$ on the continental shelf and $54,228 \mathrm{~km}^{2}(7.4 \%)$ of the open ocean adjacent to these areas of the ecoregion. High Conservation Value Areas had a mean area of 3,013 \pm SD $9,404 \mathrm{~km}^{2}$ (range 13.5-76,375 $\mathrm{km}^{2}$; Supplementary Table S4). The largest site in the portfolio is the Southern Cone Seas, which includes both oceanic and continental shelf areas in Chile and Argentina (Fig. 4).

This portfolio could protect the spawning areas of two fish species (Micromesistius australis and Dissostichus eleginoides) that sustain industrial fisheries in the region, and areas of high abundance of 18 invertebrate species that sustain artisanal fisheries. The portfolio also includes nine breeding sites of marine birds and mammals; feeding grounds of 11 top predators; areas of presence of 10 marine mammals, three algae, and corals; feeding areas of migratory shorebirds; and nine habitats (Supplementary Table S2). However, because of the exclusion of remote and isolated planning units it was not totally effective in meeting the conservation targets of nine features (Supplementary Table S2).

\section{Discussion}

There is growing concern about the potential impact of human activities on Chile's marine ecosystems (Castilla et al., 2005; Buschmann et al., 2006; Iriarte et al., 2010), and the existing marine protected areas are insufficient to represent the country's marine ecoregions fully (Guarderas et al., 2008; Advanced Conservation Strategies, 2011). For example, the Francisco Coloane Marine Protected Area covers only $0.075 \%$ of the channels and fjords ecoregion. In this context our results should prove valuable in identifying High Conservation Value Areas and provide a potential opportunity to promote a network of marine protected areas. 

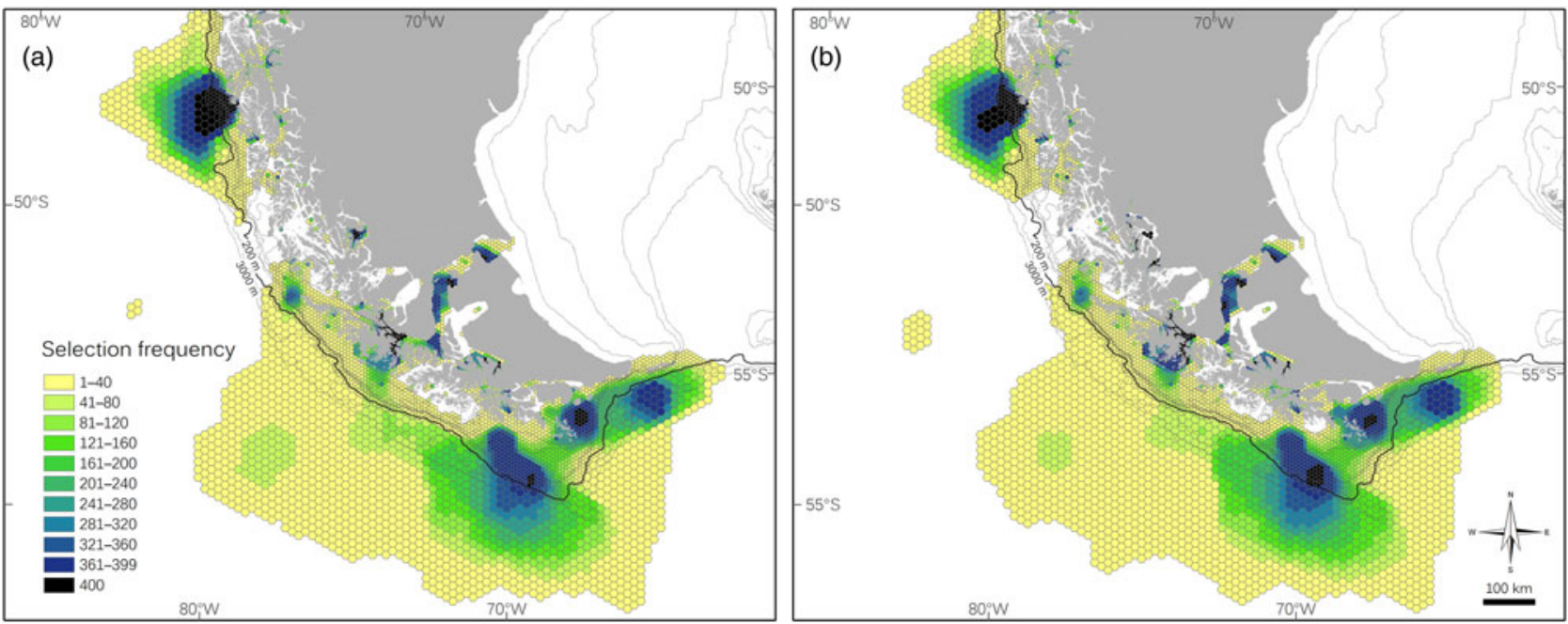

FIG. 2 Comparison of spatial array of High Conservation Value Areas identified for two planning scenarios in the channels and fjords of the southern Chile ecoregion (Fig. 1), based on the frequency of selection of planning units across 400 optimal solutions of Marxan. (a) Scenario I included all planning units within the Francisco Coloane Marine Protected Area. (b) Scenario II included all planning units within the Francisco Coloane Protected Area and excluded those that overlapped Appropriate Areas for Aquaculture in Scenario I.

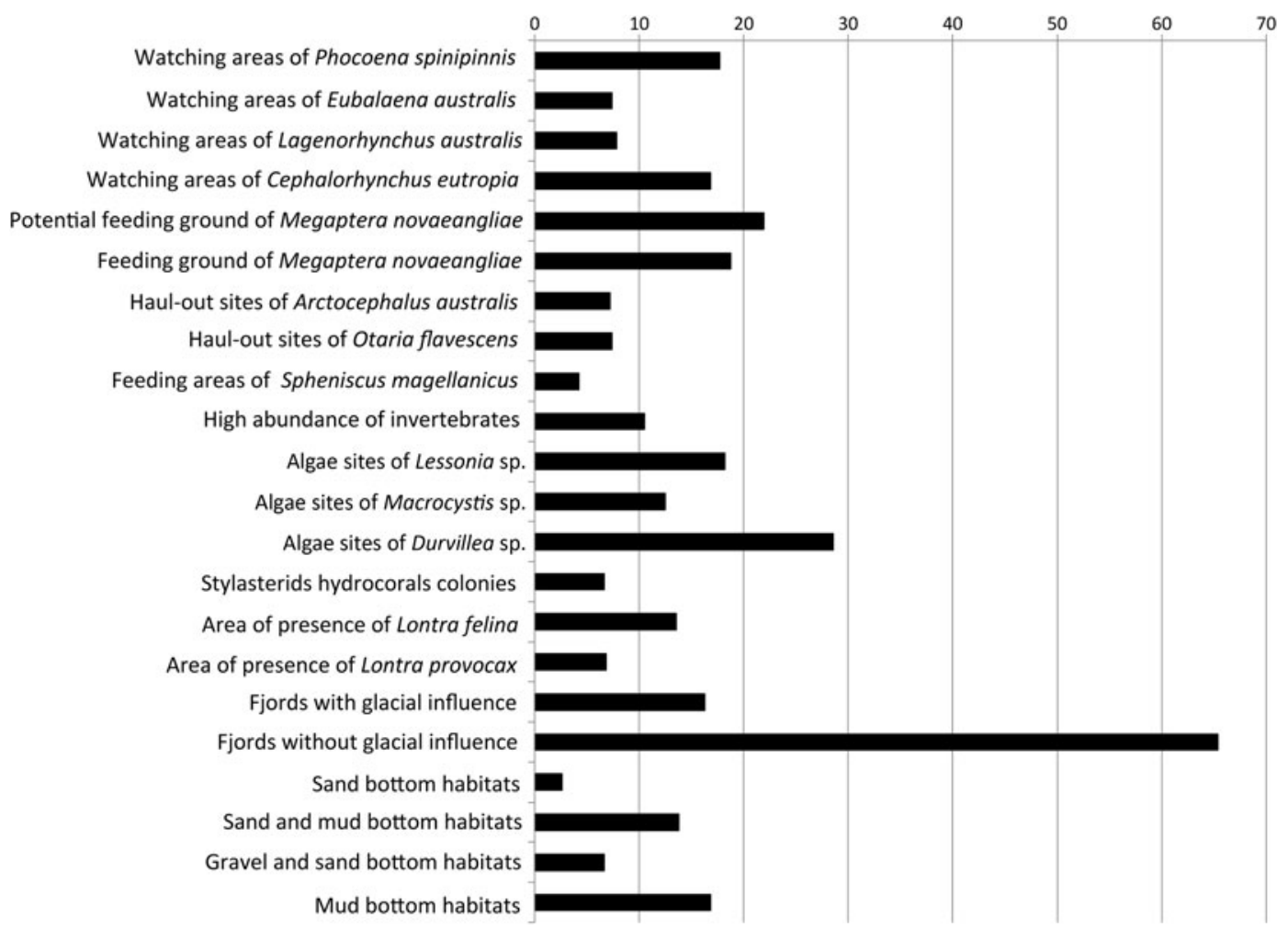

FIG. 3 Percentage overlap between the distribution range of conservation features and Appropriate Areas for Aquaculture in the channels and fjords of the southern Chile ecoregion (Fig. 1).

They also identify a preliminary network of conservation areas that could be developed to improve conservation of Chile's marine biodiversity. This network could become the first step towards achieving the conservation goals set by the Convention on Biological Diversity (CBD, 2011).
This portfolio may therefore guide future decisions about marine policy, including where to invest conservation resources, the identification of potential conflicts, and the identification of biodiversity offset areas to mitigate the negative effects of development projects. 


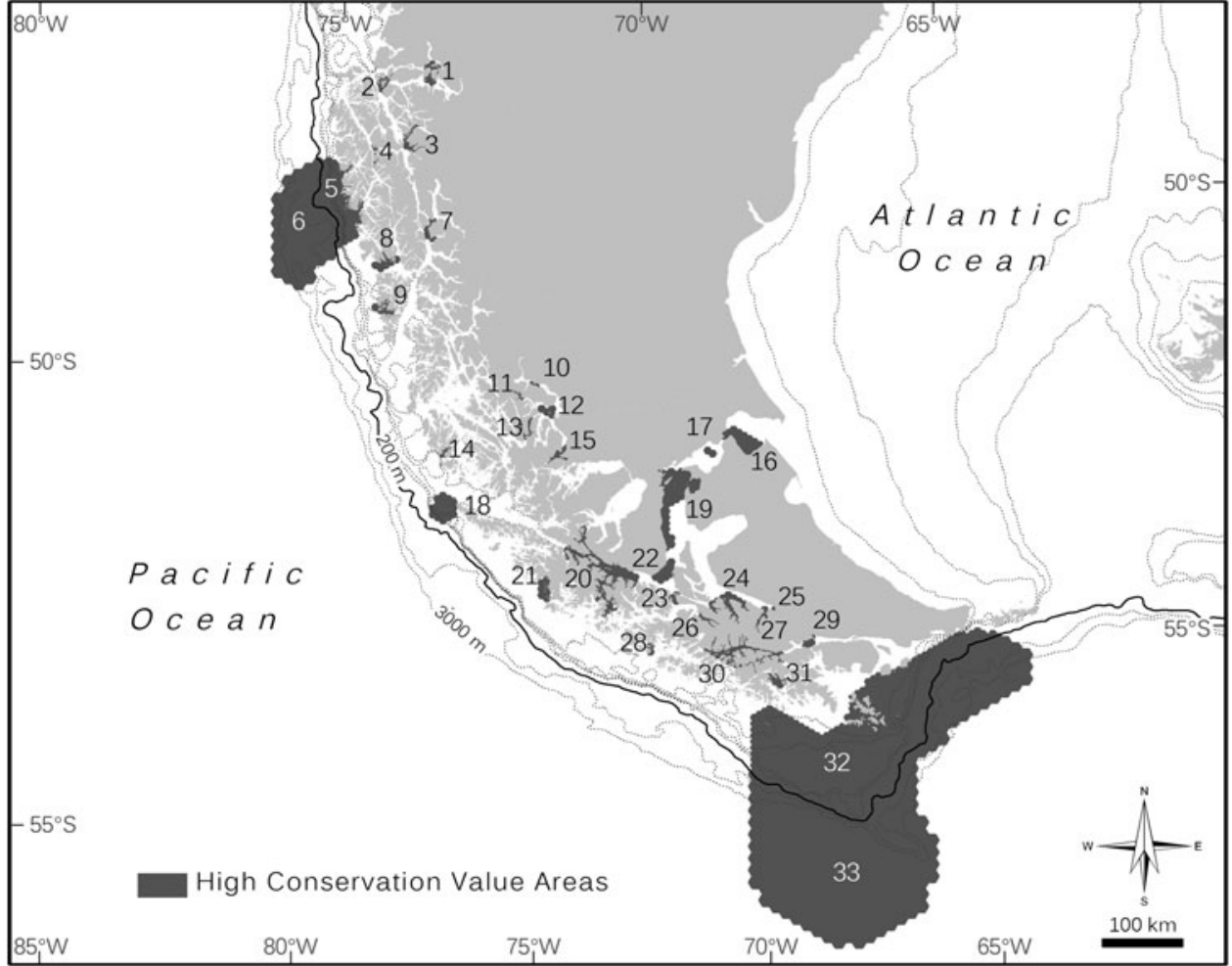

FIG. 4 Proposed portfolio of High Conservation Value Areas for the channels and fjords of the southern Chile ecoregion, based on the best solution output (achieving targets at the minimum cost) obtained for scenario II using Marxan. Site numbers correspond to those in Supplementary Table $\mathrm{S}_{4}$.
Although national, coarse-scale assessments have been carried out to identify areas for marine conservation in Chile, our work is the first attempt to identify High Conservation Value Areas at a finer resolution. Our results concur, in general, with previous broad-scale assessments (Supplementary Table S4). Regardless of which features and targets are used, 16 of the 33 areas we identified are located within latitudinal bands of 0.5 that were defined by Tognelli et al. (2009) as irreplaceable. Leiva et al. (2010) also identified four sites of high priority for the conservation of the open ocean portion of the ecoregion, two of which showed a high degree of concurrence with the oceanic areas we identified. We also observed a significant overlap between our results and those reported by IEB (2010). The Chilean Ministry of Environment chose a set of six marine priority areas for conservation, based on an expert-driven approach (CONAMA, 2002). Although this involved biases associated with experts' uneven knowledge of regions and taxa (Cowling et al., 2003), five sites identified by CONAMA overlap with our results. The two northernmost areas we identified in the ecoregion are included in a marine protected area proposal being promoted by OCEANA and the Tortel Council (2009). Thus both broad-scale systematic conservation planning and expertdriven approaches support our portfolio of High Conservation Value Areas, even though it also reflects several gaps in marine biodiversity conservation for the ecoregion.

\section{Conservation and Appropriate Areas for Aquaculture}

The conservation scenarios did not change substantially when the Appropriate Areas for Aquaculture designated by the government were excluded from the analysis. Although solutions for scenario II may be more useful to minimize potential conflicts between conservation and aquaculture, the Appropriate Areas for Aquaculture are located in remote places where fine-scale data are lacking, and the lack of potential conflict may reflect this. Scenario I had the lowest objective function value but the area was larger and involved more planning units than scenario II. Only $4 \%$ of the available planning units $(9,746)$ were locked by the presence of Appropriate Areas for Aquaculture, and the distribution of conservation features under analysis was assumed to be homogeneous, because of the lack of information on densities or population sizes in each planning unit.

Despite the fact that it was possible to create a network that met all our targets even when the Appropriate Areas for Aquaculture were excluded, there was a significant degree of overlap between the ranges of several conservation features and the areas designated for aquaculture. Consequently, the potential impacts of salmon farming on conservation targets outside High Conservation Value Areas may be important and should be minimized. Environmental concerns regarding salmon farming in Chile include modification of benthic communities, increased nutrient loads in coastal waters and harmful algal 
blooms, increased harvests of wild fish for fish feed, use of chemicals, and escape of farmed salmon into the wild (Buschmann et al., 2006). Interactions between aquaculture facilities and marine mammals may include injury and mortality as a result of entanglement (Würsig \& Gailey, 2002).

Given the expected growth of aquaculture in the ecoregion we recommend that each proposed aquaculture concession be evaluated with reference to our portfolio of High Conservation Value Areas and the underlying spatial database of biodiversity information. Market standards for aquaculture certification have been developed to minimize the effects of salmon farming on critical habitats and species, including protected areas and High Conservation Value Areas (Steering Committee of the Salmon Aquaculture Dialogue, 2012); for example, a specific indicator has been designed to ensure a farm is aware of any nearby critical, sensitive or protected areas, understands the impacts it could have on those areas, and has an operational plan in place to address any potential impacts. Our database and analysis may be used to address potential impacts of aquaculture concessions on the marine biodiversity of the region and to define mitigation or offset strategies on a case-by-case basis (BBOP, 2009).

Our results were shared with the government and included in its coastal zoning process. Based on our recommendations areas along the coasts of Tierra del Fuego island that had been previously destined for salmon farming were no longer designated for this purpose.

\section{Data analyses}

Our analysis was conducted using two sizes of planning unit. The smaller planning units on the continental shelf were used to capture the detail of channels and fjords, and data resolution was higher for inland waters. Ardron et al. (2010) warned about a bias effect in the use of different-sized planning units and described the effects of using larger offshore units and smaller inshore ones. They suggested that small planning units were chosen almost twice as often as larger ones. Although Ardron et al. (2010) also recognized that some planning processes require the use of natural units of analysis that may be of variable size, our results must be interpreted cautiously because the different-sized planning units could bias site selection towards coastal areas. However, as most of the conservation features with coastal distribution are not found in offshore waters and vice versa we do not expect a significant bias in our analysis.

Considering the growing pressure of human activities and potential conflicts of interest in coastal waters, we also increased the cost of inshore planning units. In our analysis the cost of each planning unit did not directly reflect the potential economic value of its alternative human uses (opportunity cost) or the direct costs of implementing conservation areas. In terms of incorporating costs into the analysis we assumed that implementation of conservation areas would be less difficult in oceanic waters than in inland waters, where there are greater demands for human use, and political barriers to conservation. To consider more comprehensively the multiple costs of a portfolio of High Conservation Value Areas and improve the chances of its implementation we are beginning a process that incorporates economic and social costs into the analysis. The use of Marxan with Zones (Watts et al., 2009) will facilitate optimal allocation of resources to multiple-zone configurations, incorporating ecological, social and economic costs into a systematic planning framework.

The robustness of the results of this analysis relies on the accuracy and representativeness of the information used. This marine ecoregion combines fjords and difficult-to-navigate rugged coastlines with unfavourable weather conditions during most of the year, which make it difficult to access remote areas and develop systematic research on species abundance and distribution. This is reflected in the quality and representativeness of the data and is a weakness of the analysis. However, we used the most reliable and up-to-date information provided by experts, combined with the opinions of a wide range of stakeholders.

In this context two weaknesses in the datasets should be considered. We used sighting data collected opportunistically as a proxy to identify distribution areas for several species, and this approach involves biases. Sightings are correlated to navigation routes, populated areas and human activities, and may also be biased by weather conditions. Secondly, the research effort on distribution of habitats and species has not been spatially homogeneous and has been limited in remote areas with harsh environments. In such cases inaccurate or incomplete data should not limit the development of conservation planning efforts (Grantham et al., 2008). Inherent limitations of spatial analysis and conservation planning, mostly related to data quality and availability, highlight the importance of developing adaptive processes and explicit mechanisms to revise and update the information to be used over the next 510 years, incorporating new findings to ensure this portfolio of High Conservation Value Areas is kept up to date. Future efforts should be directed to adapt and improve the analysis by expanding surveys to include other important features and/or enhanced information on the distribution of conservation objects used; improving distribution data where feasible (i.e. modelling distributions); incorporating the potential effects of threats; considering the financial, political and social feasibility or costs of implementation (Murdoch et al., 2010); using informed opportunism guided and supported by local communities (Game et al., 2010); and improving quantitative targets based on species-area curves (Heiner et al., 2011). 


\section{Acknowledgements}

We thank Claudio Venegas for allowing us to conduct a workshop in the Magallanes University, and the Foundation Montagu and the Ministry of Economy of Chile for their generosity in making the workshop in Santiago possible. We gratefully acknowledge the assistance of Susan Arismendi, Claudio Moraga, Macarena Isla, Ricardo Muza, Raúl San Martín, and Viviana Urbina. We also thank all the participants in this process, particularly Edgardo Casanova and the Borde Costero Technical Office of the Regional Government. Karl Didier, Claudio Campagna, Miriam Fernández, Cristina Abaca and two anonymous reviewers provided constructive comments.

\section{References}

Advanced Conservation Strategies (2011) A Coastal-Marine Assessment of Chile. A report for The David and Lucile Packard Foundation, Los Altos, USA

Aguayo-Lobo, A., Acevedo, J. \& Olave, C. (2007) Actualización de las bases para una estrategia para la conservación de mamíferos marinos en la región de Magallanes y Antártica Chilena. Fundación Centro de Estudios del Cuaternario, Fuego-Patagonia y Antártica, Punta Arenas, Chile.

Ardron, J.A., Possingham, H.P. \& Klein, C.J. (2010) Marxan Good Practices Handbook, Version 2. Pacific Marine Analysis and Research Association, Victoria, Canada.

Ball, I.R. \& Possingham, H.P. (200o) Marxan (v. 1.8.2): Marine Reserve Design using Spatially Explicit Annealing. The University of Queensland, Brisbane, Australia.

Ball, I.R., Possingham, H.P. \& Watts, M. (2009) Marxan and relatives: software for spatial conservation prioritization. In Spatial Conservation Prioritization: Quantitative Methods and Computational Tools (eds A. Moilanen, K.A. Wilson \& H.P. Possingham), pp. 185-195. Oxford University Press, Oxford, UK.

BBOP (Business and Biodiversity Offesets Programme) (2009) Biodiversity Offset Design Handbook. BBOP, Washington, DC, USA.

Bird Life International (2004) Tracking Ocean Wanderers: The Global Distribution of Albatrosses and Petrels. Results from the Global Procellariiform Tracking Workshop, 1-5 September, 2003, Gordon's Bay, South Africa. BirdLife International, Cambridge, UK.

Buschmann, A.H., Riquelme, V.A., Hernández-González, M.C., Varela, D., Jiménez, J.E., Henríquez, L.A. et al. (2006) A review of the impacts of salmonid farming on marine coastal ecosystems in the southeast Pacific. Journal of Marine Science, 63, 1338-1345.

Castilla, J.C., Uribe, M., Bahamonde, N., Clarke, M., Desqueyroux-Fáundez, R., Kong, I. et al. (2005) Down under the southeastern Pacific: marine non-indigenous species in Chile. Biological Invasions, 7, 213-232.

CBD (Convention on Biological Diversity) (2011) Strategic Plan for Biodiversity 2011-2020, including Aichi Biodiversity Targets. Http://www.cbd.int/sp/ [accessed 5 February 2013].

CONAMA (2002) Diagnóstico y propuesta para la conservación de la biodiversidad en la XII Región. CONAMA, Punta Arenas, Chile.

Cowling, R.M., Pressey, R.L., Sims-Castley, R., le Roux, A., BaArd, E., Burgers, C.J. \& Palmer, G. (2003) The expert or the algorithm? Comparison of priority conservation areas in the Cape
Floristic Region identified by park managers and reserve selection software. Biological Conservation, 112, 147-167.

Díaz Herrero, S. \& León Muñoz, J. (2006) Actas taller científico: investigación ambiental en la salmonicultura Chilena, gasto o inversión? WWF Chile, Valdivia, Chile.

Falabella, V., Campagna, C. \& Croxall, J. (2009) Atlas del Mar Patagónico: Especies y Espacios. Wildlife Conservation Society and BirdLife International, Buenos Aires, Argentina.

Fernández, M. \& Castilla, J.C. (2005) Marine conservation in Chile: historical perspective, lessons, and challenges. Conservation Biology, 19, 1752-1762.

Friedlander, A.M., Ballesteros, E., Beets, J., Berkenpas, E., Gaymer, C.F., Gorny, M. \& Sala, E. (2013) Effects of isolation and fishing on the marine ecosystems of Easter Island and Salas y Gómez, Chile. Aquatic Conservation: Marine and Freshwater Ecosystems, 23, 515-531.

Galvez, M., Farías, A., Montecinos, Y. \& Hucke-Gaete, R. (2010) Planificación sistemática y Áreas de Alto Valor de Conservación (AAVC) en la Ecorregión Chiloense. WWF Chile, Santiago, Chile.

Game, E.T., Lipsett-Moore, G., Hamilton, R., Peterson, N., Kereseka, J., Atu, W. et al. (2010) Informed opportunism for conservation planning in the Solomon Islands. Conservation Letters, $4,38-46$.

Gobierno Regional (2011a) Memoria y propuesta de zonificación del borde costero: Provincia de Magallanes. Punta Arenas, Chile.

Gobierno Regional (2011b) Memoria y propuesta de zonificación del borde costero: Provincia de Última Esperanza. Punta Arenas, Chile.

Gobierno Regional (2011c) Memoria y propuesta de zonificación del borde costero: Provincia de Tierra del Fuego y Antártica Chilena. Punta Arenas, Chile.

Grantham, H.S., Moilanen, A., Wilson, K.A., Pressey, R.L., Rebelo, T.G. \& Possingham, H.P. (2008) Diminishing return on investment for biodiversity data in conservation planning. Conservation Letters, 1, 190-198.

Guarderas, A.P., Hacker, S.D. \& Lubchenco, J. (2008) Current status of marine protected areas in Latin America and the Caribbean. Conservation Biology, 22, 1630-1640.

Häussermann, V. \& Försterra, G. (eds) (2009) Marine Benthic Fauna of Chilean Patagonia. Illustrated Identification Guide. Nature in Focus, Santiago, Chile.

Heiner, M., Davaa, G., Kiesecker, J., McKenney, B., Evans, J., Enkhtsetseg, T. et al. (2011) Identifying Conservation Priorities in the Face of Future Development: Applying Development by Design in the Grasslands of Mongolia. The Nature Conservancy, Arlington, USA.

IEB (Instituto de Ecología y Biodiversidad) (2010) Estudio de análisis de omisiones y vacíos de representatividad en los esfuerzos de conservación de la biodiversidad en Chile. IEB, Santiago, Chile.

Iriarte, J.L., González, H.E. \& Nahuelhual, L. (2010) Patagonian fjord ecosystems in southern Chile as a highly vulnerable region: problems and needs. $A M B I O, 39,463-466$.

Leiva, S., Soto, E. \& Araya, G. (2010) Propuesta de parques marinos para Chile. Greenpeace Chile, Santiago, Chile.

LeÓN Muñoz, J. (2006) Sinopsis de los impactos y la gestión ambiental en la salmonicultura chilena. Informe Técnico de Consultoría. WWF Chile, Valdivia, Chile.

Margules, C.R. \& Pressey, R.L. (2000) Systematic conservation planning. Nature, 405, 243-253.

McDonnell, M.D., Possingham, H.P., Ball, I.R. \& Cousins, E.A. (2002) Mathematical methods for spatially cohesive reserve design. Environmental Modeling and Assessment, 7, 107-114.

Miloslavich, P., Klein, E., Díaz, J.M., Hernández, C.E., Bigatti, G., CAmpos, L. et al. (2011) Marine biodiversity in the Atlantic and 
Pacific coasts of South America: knowledge and gaps. PLoS ONE, 6(1), e14631.

Murdoch, W., Ranganathan, J., Polasky, S. \& Regetz, J. (2010) Using return on investment to maximize conservation effectiveness in Argentine grasslands. Proceedings of the National Academy of Sciences of the United States of America, 107, 20855-20862.

OCEAnA \& Municipalidad de Tortel (2009) Propuesta Área Marina Costera Protegida de Múltiples Usos (AMCP-MU) Tortel, Patagonia Chilena. Oceana, Santiago, Chile.

PacMARA (2010) Marxan Workshop: Workshop Proceedings Report. University of British Columbia, Vancouver, Canada.

Pantoja, S., Iriarte, J.L. \& Daneri, G. (2011) Oceanography of the Chilean Patagonia. Continental Shelf Research, 31, 149-153.

Possingham, H., Ball, I. \& Andelman, S. (2000) Mathematical methods for identifying representative reserve networks. In Quantitative Methods for Conservation Biology (eds S. Ferson \& M. Burgman), pp. 291-305. Springer-Verlag, New York, USA.

Pressey, R.L., Cowling, R.M. \& Rouget, M. (2003) Formulating conservation targets for biodiversity pattern and process in the Cape Floristic Region, South Africa. Biological Conservation, 112, 99-127.

Pressey, R.L. \& Nicholls, A.O. (1989) Efficiency in conservation evaluation: scoring versus iterative approaches. Biological Conservation, 50, 199-218.

Segan, D.B., Game, E.T., Watts, M.E., Stewart, R.R. \& Possingham, H.P. (2011) An interoperable decision support tool for conservation planning. Environmental Modelling \& Software, 26, 1434-1441.

Serplac, GTZ \& Gobierno Regional de Aysén (2005) Plan Regional de Ordenamiento Territorial Región de Aysén. LOM Ediciones, Santiago, Chile.

Soazo, P.O., Rodríguez Jorquera, I., Arrey Garrido, P. \& Jaramillo, A. (2009) Chile. In Important Bird Areas of the Americas: Priority Sites for Biodiversity Conservation (eds C. Devenish, D.F. Díaz Fernández, R.P. Clay, I.J. Davidson \& I.Y. Zabala), pp. 125-134. BirdLife International, Quito, Ecuador.

Spalding, M.D., Fish, L. \& Wood, L.J. (2008) Toward representative protection of the world's coasts and oceans-progress, gaps, and opportunities. Conservation Letters, 1, 217-226.

Spalding, M.D., Fox, H.E., Allen, G.R., Davidson, N., Ferdaña, Z.A., Finlayson, M. et al. (2007) Marine ecoregions of the world: a bioregionalization of coastal and shelf areas. BioScience, 57, 573-583.

Steering Committee of the Salmon Aquaculture Dialogue (2012) Salmon Aquaculture Dialogue: Final Draft Standards for
Responsible Salmon Aquaculture. Steering Committee of the Salmon Aquaculture Dialogue, Washington, DC, USA.

Stewart, R.R., Noyce, T. \& Possingham, H.P. (2003) Opportunity cost of ad hoc marine reserve design decisions: an example from South Australia. Marine Ecology Progress Series, 253, 25-38.

Tognelli, M.F., Fernández, M. \& Marquet, P.A. (2009) Assessing the performance of the existing and proposed network of marine protected areas to conserve marine biodiversity in Chile. Biological Conservation, 142, 3147-3153.

Tognelli, M.F., Silva-García, C., Labra, F.A. \& Marquet, P.A. (2005) Priority areas for the conservation of coastal marine vertebrates in Chile. Biological Conservation, 126, 420-428.

Toropova, C., Meliane, I., Laffoley, D., Matthews, E. \& Spalding, M. (eds) (2010) Global Ocean Protection: Present Status and Future Possibilities. Agence des aires marines protégées, Brest, France; IUCN WCPA, Gland, Switzerland, Washington, DC, and New York, USA; UNEP-WCMC, Cambridge, UK; TNC, Arlington, USA; UNU, Tokyo, Japan; WCS, New York, USA.

Watts, M.E., Ball, I.R., Stewart, R.S., Klein, C.J., Wilson, K., SteinbaCK, C. et al. (2009) Marxan with zones: software for optimal conservation based land- and sea-use zoning. Environmental Modelling \& Software, 24, 1513-1521.

Wood, L.J., Fish, L., Laughren, J. \& Pauly, D. (2008) Assessing progress towards global marine protection targets: shortfalls in information and action. Oryx, 42, 340-351.

Wúrsig, B. \& Gailey, A. (2002) Marine mammals and aquaculture: conflicts and potential resolutions. In Marine Aquaculture (eds R.R. Stickney \& J.P. McVey), pp. 45-59. CAB International, Wallingford, UK.

\section{Biographical sketches}

Alejandro Vila's interests lie in conservation planning and the ecology of marine and terrestrial mammals. VALERIa Falabella's work is focused on marine spatial planning and the use of geographical information systems (GIS) to identify relevant areas for promoting marine protected areas. Mauricio GÁlvez was the Marine Program Coordinator for WWF Chile and is currently the Regional Fishery Coordinator at the WWF Southern Cone Alliance. Aldo FARIAS is a GIS specialist and his conservation interests focus on marine spatial planning in Chilean Patagonia. Daniela Droguett's work focuses on linking science with education and policy. BARBARA SAAVEDRA is interested in conservation policy and planning, and the ecology of mammals. 